turning down the presidency of the new Hungarian Republic, he applied himself instead, with the help of the Russians, over whom he had acquired considerable influence, to establishing a laboratory in Budapest. Political quarrels and disillusion followed, his closest associates were denounced and dismissed, and SzentGyörgyi, suddenly a target of political obloquy, left for America.

The indifference of his reception there came as a shock; his hyperbolic style, and perhaps the memory of the vitamin $C$ episode, exposed him to the malign machinations of power-mongers, such as

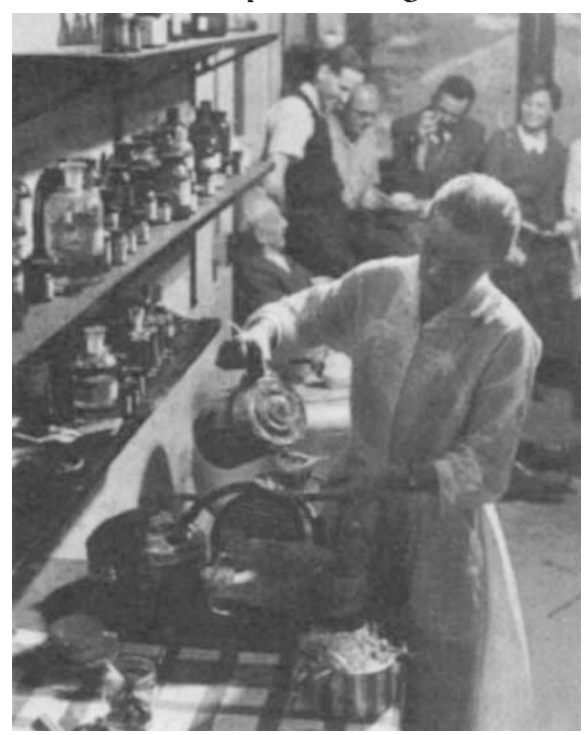

Woods Hole, 1952 - Marta Szent-Györgyi makes the tea, while Albert (left, seated) entertains his colleagues.

Detlev Bronk, and he also came under the baleful scrutiny of J. Edgar Hoover. Szent-Györgyi soon discovered that in the American academic community esteem is a highly perishable commodity (this enduring truth was memorably encapsulated in a New Yorker cartoon: "So he discovered fire and the wheel" says one caveman to another, gazing at a third, "but what has he done since?"). He reacted by becoming increasingly arrogant and dogmatic in his utterances. Yet the charm still worked; rejected by the funding agencies, he managed to persuade the meat barons of the Armour Company that their trade was muscle and that investment in his research would yield commercial treasure. The Institute of Muscle Research, which he set up at Woods Hole, did not in fact continue long with muscle research (my recollection is that, by his own account, he gave up working on muscle when it became known that myosin and actin were in separate filaments). Instead he returned to certain early and inchoate ideas about vitamin $\mathrm{C}$ and biological oxidation, and became persuaded that in them lay the key to cancer.

At this time Szent-Györgyi also became preoccupied with a vision of a new 'submolecular biology', and of the importance in biology of excited-state phenomena, such as charge transfer complexes. The requirement that was laid on him to write grant applications he considered as an affront not only to his professional standing but to logic as well, for if one knew and could describe what one was going to discover, what would be the point in discovering it? The American cancer establishment was not impressed and SzentGyörgyi reciprocated with a fine show of contempt for their ways; cancer, he once said, was coming close to keeping more people alive than it killed. Nevertheless, such was the allure of his personality that until well into his ninetieth decade he did not want for patrons or scientific followers, whose talents he often perverted.

Alas, the edifice proved to have been built of straw; Szent-Györgyi's pronouncements about the imminence of an explanation and cure for cancer became increasingly extravagant and irresponsible.

\section{In the balance}

\section{Paul Langacker}

Physics of Massive Neutrinos. By Felix Boehm and Petr Vogel. Cambridge University Press: 1987. Pp.211. £25, \$34.50.

ONE of the most intriguing questions in particle physics is whether the neutrino has mass. Experimentally, any neutrino mass must be tiny, and the highly successful standard electroweak model predicts massless neutrinos. However, it is clear that the standard model is not the ultimate theory of nature. Most theories of the new physics that must exist below $10^{-16} \mathrm{~cm}$ predict a non-zero mass at some level, and often that it is of the peculiar Majorana character, which means that there is no fundamental distinction between neutrinos and antineutrinos.

Neutrino mass is also of vital importance for astrophysicists. The Universe is presumably filled with enormous numbers of neutrinos left over from the first second of the Big Bang. If these have even a small mass, in the $10 \mathrm{eV} \mathrm{c}^{-2}$ range, they would dominate the energy density of the Universe and account for the missing (dark) matter. Furthermore, coherent interactions of very light $\left(\leqslant 10^{-2} \mathrm{eV} \mathrm{c}^{-2}\right)$ neutrinos in the Sun could account for the missing solar neutrinos in the famous ${ }^{37} \mathrm{Cl}$ experiment.

The subject is of bewildering complexity, however. Experiments and the theoretical ideas needed to interpret them overlap particle, nuclear and astrophysics, and the field is confused by conflicting experiments and calculations. Boehm and Vogel's little book goes a long way towards clarifying these difficult issues. It provides a readable and concise, but
The advances in molecular biology, that were opening up cancer research, passed him by and in the end it became clear that nothing remained but an old man's unreasoning obsession. The foundation, set up to support his cancer research by a philanthropic lawyer, wholly in his thrall, collapsed in squalor and recrimination; influenced by his young wife, SzentGyörgyi became alienated from his family and friends. He had become a relic, a monstre sacré, lonely embittered and unfulfilled. He died at 93 , still pursuing his star, for, as he had said, he knew no other way to live. His was the true tragedy of old age, which Oscar Wilde put into the mouth of Lord Henry Wotton in The Picture of Dorian Gray - not that one is old, but that one is young.

Walter Gratzer is in the Medical Research Council Cell Biophysics Unit, King's College London (KQC), 26-29 Drury Lane, London WC $2 B 5 R L, U K$.

still fairly thorough, guide to most aspects of the field.

The formalism of Majorana and Dirac neutrinos, theoretical models and neutrino interactions are briefly described. There is an excellent treatment of the various (conflicting) tritium beta-decay experiments, an overview of the varied experiments searching for small mixings with possible heavy neutrinos, and thorough accounts of all aspects of double beta-decay and neutrino oscillations (two subjects on which the authors have worked extensively). There are also short discussions of cosmological implications and the impact of Supernova 1987A.

The book provides a balanced treatment of conflicting experiments. It is generally accurate and complete, though there are occasional lapses (such as wrong attribution of the Gelmini-Roncadelli Majoron model and omission of any mention of the suggestive CERN PS-191 oscillation results). Perhaps its main weakness is in the treatment of the solar neutrino problem. A discussion of the several parameter ranges relevant to matter-induced oscillations and how they could be distinguished from alternative models would have been useful.

Overall, this is an excellent introduction and guide to an important and complex field.

Paul Langacker, currently at DESY, Notkestrasse 85, D-2000 Hamburg 52, FRG, is a Professor of Physics at the University of Pennsylvania.

\title{
New in reference
}

- Information Resources in Toxicology, 2nd edn, by P. Wexler. (Elsevier, Dfl. 195, \$85.)

- Dictionary of Genetics and Cell Biology by N. Maclean. (Macmillan, hbk $£ 27.50$, pbk f10.95.) In the US, New York University Press. - Dictionary of Microbiology and Molecular Biology, 2nd edn, by P. Singleton and D. Sainsbury. (Wiley, $£ 69, \$ 150$.) 